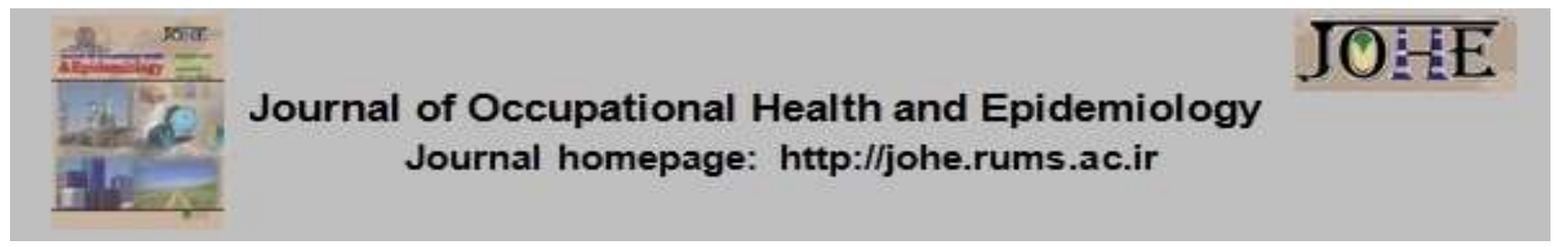

\title{
Noise assessment and sound map projection using Surfer and Noise At Work tools in a tire manufacturing complex in Iran, 2018
}

\author{
Davood Hasanvand ${ }^{1}$, Sajad Zare², Mohammad Reza Ghotbi-Ravandi ${ }^{*}$
}

1- MSc Student of Occupational Health, Student Research Committee, School of Public Health, Kerman University of Medical Sciences and Health Services, Kerman, Iran.

2- Assistant Prof., Department of Occupational Health, School of Public Health, Kerman University of Medical Sciences and Health Services, Kerman, Iran.

3- Associate Prof., Department of Occupational Health, School of Public Health, Kerman University of Medical Sciences and Health Services, Kerman, Iran.

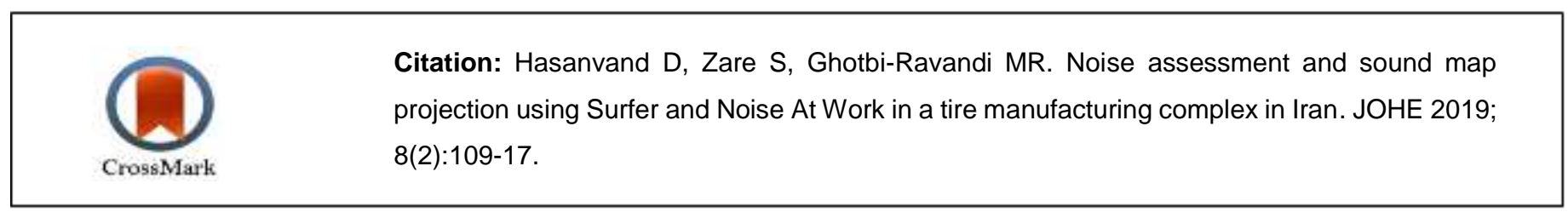

Article Info
*Corresponding author:
Mohammad Reza Ghotbi-
Ravandi,
E-mail:
ravandir@yahoo.co.uk

\section{Article history}

Received: Apr, 2019

Accepted: May, 2019

10.29252/johe.8.2.109

Print ISSN: 2251-8096 Online ISSN: 2252-0902

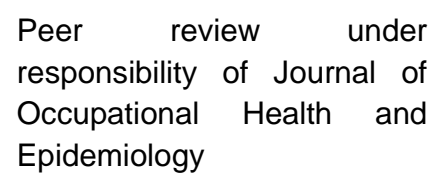

\section{Abstract}

Background: Noise pollution is one of the common physical harmful factors in many work environments. The current study aimed to assess the personal and environmental noise level and project the sound map of an Iranian tire manufacturing complex using Surfer V.14 and Noise At Work tools.

Materials and Methods: This descriptive study was conducted in the curing hall [including curing, sandblast, and trimming units] of a tire manufacturing complex in 2018 . Following ISO 9612:2009, Casella Cel-320 was used to measure the personal noise level, while CEL-450 sound level meter (Casella-Cel, the UK) was employed to assess the environmental sound pressure level [ISO 1996-1:2016].The sound and isosonic maps were projected using Surfer V.14 and Noise At Work.

Results: The results indicated that the highest received dose (163.30\%) and personal equivalent sound level [87.13 dBA] were recorded for workers in the curing unit. The results of measuring the environmental sound pressure level also revealed that out of 101 measurement stations in the curing unit, 76 stations $(75.25 \%)$ were hazardous areas (over $85 \mathrm{dBA})$.

Conclusions: Over $75 \%$ of the curing hall had a sound pressure level greater than 85 dBA. The curing unit was found to be the most dangerous area in terms of noise pollution. It is, therefore, necessary to implement noise control measures (e.g., the use of screens, barriers, enclosures), apply hearing conservation programs, and conduct auditory tests on workers in this unit.

Keywords: Participation, Autonomy, Stroke, Iran.

\section{Introduction}

Noise is one of the common harmful factors in work environments (1-3). Noise is defined as an undesirable sound caused by activities in a particular time and at a specific rate. It can cause health problems and affect humans' environmental comfort (4). Approximately in all industries, noise generated is more threatening than any other occupational pollutant. Thus, noise-related disorders, which constitute a major challenge of the industrial world, affect many workers in the work environments (5) Technological machinery is an indispensable component of production processes. If such machinery is not maintained properly, it will generate harmful noise in the work environment (4). Noise is associated with some health problems like stress (6), stimulation of peripheral blood vessels and hypertension $(7,8)$, cardiovascular problems $(9,10)$, fatigue, sleep disorders, psychological disorders, and hearing loss $(11,12)$. Almost 30 
million workers in the United States (13), and 4 to 5 million workers in Germany (accounting for $12 \%$ to $14 \%$ of the workforce in this country) are exposed to excessive sound pressure levels, as defined by the World Health Organization (WHO) (14). About 2 million workers are exposed to dangerous noise in their workplaces in the Iran (15). Noise also negatively affects the human capability in understanding high frequency sounds. That is, people may perceive sounds but they are unable to clearly understand what other people say in conversations due to auditory masking in the work environment. Disruption in conversations can affect workers' performance in the work environment $(16,17)$. Indeed, two workers may not be able to communicate their messages and instructions clearly in noisy environments; a phenomenon that may disrupt the working process and increase the likelihood of work-related accidents. Excessive noise may also hinder communication among workers in emergency cases (5). Noise is defined as an unwanted sound caused by activities in a particular time and at a specific rate. It can cause health problems and affect humans' environmental comfort (5). Noise waves are generated as a result of the vibration of some objects. Such waves are emitted through a rotary movement and create a sequence of compressed and expanded waves in the medium (water, air, etc.) $(18,19)$. In industry, noise is produced through the mixing of various components such as fluid disturbances, displacement and vibration of machine parts, and temperature differences (4). A major percent of noise in work environments is produced by moving parts of machines. In particular, vibrations caused by friction, shocks, or imbalance of rotating machine parts (e.g. shear compressors, turbines, pumps, and blowers) generate a lot of noise (20). Atmaca et al. (2005) investigated industrial noise and its impacts on humans in various factories, and concluded that $61 \%$ of workers suffered from neurological disorders, while $31 \%$ had hearing disorders (21). Esmaeli et al. (2006) assessed the amount of noise pollution produced by air compressors in the air conditioning unit of a factory. The results indicated that the noise generated by the compressors exceeded the standard level. The researchers argued that in order to reduce noise from all sources (e.g. air outlet pipes and air intake valves), silencers and mufflers should be installed in the outlet of noise generating sources (22). In another study, Hakimi et al. (2006) utilized Sound Plan to develop a model for measuring the volume of noise emission in the outdoor space of a new condensing unit of Sarcheshmeh Copper Complex, Kerman. They showed that installing a module in the air outlet reduced the sound pressure level by $20 \mathrm{~dB}(23)$.

To date, no study has investigated the personal and environmental sound pressure level and projected the sound map in this factory. Furthermore, since the industrial technology is developing regularly, it is necessary to gauge occupational risk factors like physical harmful factors (especially noise) in this factory. Thus, the present study sought to:

1- To assess workers' personal sound pressure level.

2- To measure the environmental sound pressure level.

3- To project the sound map and isosonic map (contour lines) using Noise At Work.

4- To determine danger, caution, and safe areas in the curing unit of the tire complex.

\section{Materials and Methods}

This study adopted a descriptive design and was conducted in the curing hall of a tire factory in 2018. The personal sound pressure level was measured among 66 workers, who were selected through the census sampling technique. The environmental sound pressure level was also assessed in the curing unit. Surfer V.14 and Noise At Work were used to project the sound and isosonic map. Also this study was approved by the Ethics Committee of kerman university of medical sciences. Ethics code (IR.KMU.REC.1397.392).

Noise At Work is an extremely easy-to-use tool for reporting any type of measurement as interpolated contours. It is used by industrial and occupational hygienists to report noise at work and other type of measurements in indoor and outdoor workspaces. Key words are fit for purpose, easy to use, and cost efficient. Noise At Work has 2 optional add-ons. Noise Dose calculations based on LEX or TWA and Noise Prediction with screening calculation according to VDI 2720 (24). The interpolation method of Noise At Work is based on an advanced, fast, and smart triangulation technique with an additional smoothing option. Calculations are done automatically while entering or importing the measurement data. This means that the software is fully interactive and shows the effect of changes in the real-time input data (24).

The selected industry was a tire manufacturing complex in Iran. A total number of 60 curing press machines were organized in the complex in 4 rows, with 15 machines in each row. There was a distance of $2 \mathrm{~m}$ between every two machines installed in a $100 \times 50 \times 90 \mathrm{~m}$ hall. Each of these factors (i.e. number of machines, their distance from each other, the dimensions of the hall, etc.) can contribute to the production of noise. Thirty twin PLC tire curing press 
machines were mounted in the middle of the hall in two rows facing each other. They were used to cure tires by applying direct heat under compressed air. Further, there were 30 singleton OTR tire curing press machines installed on the two sides of the hall. In these machines, the compressed air and vapor were applied to produce 70 types and sizes of tire for cars, trucks, heavy, semi-heavy and lightweight machinery, and agricultural machinery.

A total of 2100 to 2300 workers were working in the factory at the time of the study. Of these workers, 66 worked in the curing hall in three work shifts (22 workers in each shift, with the morning shift lasting from 8 a.m. to 4 p.m.). The curing hall had an area of $5000 \mathrm{~m} 2$, while the sandblast and trimming units covered an area of $200 \mathrm{~m} 2$. Casella Cel-320 Noise Dosimeter was used to measure the equivalent sound level according to ISO 9612:2009. Prior to the measurements, Cel-110/2 calibrator was used to calibrate the noise dosimeter $(25,26)$. Given that the workers had a break of 2 hours during the 8hour work shift, the degree of their exposure to noise was measured for 6 hours (while they were working). During their break time, the workers left the hall and rested in another place. Their personal exposure to noise was also measured during these 2 hours. The following formulas were used to calculate the measure of workers' exposure to noise and equivalent sound level during the 8-hour work shift (27):

Measurement of the dose of workers' exposure to noise:

$$
\operatorname{Dose}(\%)=\frac{8}{T_{a}} \times 100
$$

Where $\mathrm{D}$ is noise dose (\%) and Ta is the permissible exposure time based on the environmental sound pressure level (hr).

The standard dose of noise exposure for Iran is calculated through the following equation:

$$
D(\%)=12.5 \sum_{i=1}^{n} t_{i} \text { anti } \log \left(\frac{S P L_{i}-85}{10}\right)
$$

Measurement of equivalent sound level for 8-hour exposure

The following formula was used to measure 8-hour equivalent sound level (27):

$$
\operatorname{Leq} .8 \mathrm{~h}(\mathrm{~dB})=10 \log \left[\frac{1}{8} \sum_{\mathrm{i}=1}^{\mathrm{n}} \mathrm{t}_{\mathrm{i}} \times 10^{\frac{1 \mathrm{pi}}{10}}\right]
$$

Where Leq.8h is the equivalent sound level for 8hour exposure $[\mathrm{dB}]$, ti is the exposure time (hr), and
Lpi is the measured equivalent sound level in the rest room and the work environment $(\mathrm{dB})$.

CEL-450 sound level meter (Casella-Cel, the UK) was used to measure environmental sound pressure level in the selected areas based on the $\mathrm{dBA}$ frequency scale and slow mode. Prior to every measurement, the sound level meter was calibrated using Cel-110/2 calibrator. In the first phase of the study, the environmental sound pressure level was measured following ISO 9612:2009 and ISO $11200: 2014(25,28)$. The aim was to determine the measure of noise pollution in the units and identify the major sources of noise $(29,30)$. To this end, the study units were divided into equal size squares $(5 \times 5 \mathrm{~m} 2)$, with measurements being carried out at the center of each square (31-33). In the studied industrial complex, environmental sound was relatively continuous and there were few sound level fluctuations in the course of time. Therefore, at least three measurements were conducted in each selected station and the logarithmic average of these three measurements was considered as indicative of the sound pressure level of that station. Given that the study aimed at assessing noise pollution of the curing complex, dBA was used as the measurement scale of sound frequency. In line with ISO 9612:2009, the microphone was placed roughly in the place where the workers' head was located (though the workers were not present there during measurements). The microphone was placed $1.55 \pm 0.075 \mathrm{~m}$ above the earth surface [25, 34]. If the measurement square coincided with a machine or a place where measurement was impossible, the station was regarded as a blind spot and was removed from the total number of measurement stations. As a result, some areas like the places where the curing press machine was located, the terminal of raw materials, clandere unit (conveyors for moving tires), the staff's rest room, and some parts of the sandblast unit were regarded as blind spots. The procedure used for calculating average environmental sound pressure level is described below:

The following formula was used to calculate the average environmental sound pressure level in the selected stations (27):

$$
\overline{L P}(d B)=\left\lceil\frac{1}{N} \sum_{1}^{n} 10^{S P L / 10}\right\rfloor
$$

Where $\overline{L P}$ is the average sound pressure level in each station $(\mathrm{dB})$, SPLi is the measured sound pressure level in each station $(\mathrm{dB})$, and $\mathrm{N}$ is the number of measurements.

Sound and isosonic (contour) maps are two common procedures for expressing and assessing 
the environmental sound pressure level. These maps are used to identify ranges of sound pressure level in different areas of the workshop. To project the maps, the hall was divided into equal size squares of $5 \times 5 \mathrm{~m} 2$. Measurements were carried out at the center of each square. Then, the results were fed into the factory's station plan and were subsequently fed into Surfer V.14 (35), and Noise At Work (35) in the form of an input file. The sound and isosonic maps were then projected in light of the three ranges of the sound pressure level (explicated below). In the isosonic maps, the contour areas were connected, forming isosonic curves. Similar to topographic maps, these curves indicate the ranges of sound pressure level:

- Safe range (SPL $<65 \mathrm{dBA})$ marked green

- Caution range (65 < SPL $\leq 85$ dBA) marked yellow

- Danger range (SPL > 85 dBA) marked red

The output was presented as a colored map of workshop contours, in which safe, caution, and danger areas were identified, with the last area requiring noise control measures (27). Therefore, in order to project the sound map and contour lines in Surfer V.14 with the aim of the better illustration of noise emission in the curing hall and identification of caution and danger areas, the differences between measured levels and contours were set at $3 \mathrm{~dB}$ and $0.9 \mathrm{~dB}$, respectively.

SPSS (version 22) was used for data analysis. Descriptive statistics (i.e. mean and standard deviation) were calculated for the quantitative variables.

\section{Results}

Table 1 illustrates the results of noise dosimetry and the 8-hour equivalent sound level. As it is observed, the highest dose (163.30\%) was recorded for workers in the curing unit. Thus, they were exposed to the highest personal sound pressure level (87.13 dBA).

Table 1: The results of measuring personal sound pressure level $(\mathrm{N}=66)$

\begin{tabular}{|c|c|c|c|c|c|c|c|}
\hline \multirow{2}{*}{ Unit } & \multirow{2}{*}{$\begin{array}{c}\text { Number } \\
\text { of } \\
\text { workers }\end{array}$} & \multicolumn{2}{|c|}{ Presence in places (hr) } & \multicolumn{2}{|c|}{$\begin{array}{c}\text { Personal sound pressure } \\
\text { level (dBA) }\end{array}$} & \multirow{2}{*}{$\begin{array}{l}\text { Received } \\
\text { dose (\%) }\end{array}$} & \multirow{2}{*}{$\begin{array}{c}\text { 8-hour } \\
\text { equivalent } \\
\text { sound level } \\
\text { (dBA) }\end{array}$} \\
\hline & & Workshop & $\begin{array}{l}\text { Rest } \\
\text { room }\end{array}$ & Workshop & $\begin{array}{l}\text { Rest } \\
\text { room }\end{array}$ & & \\
\hline Curing & 51 & 6 & 2 & 88.30 & 67 & 163.30 & 87.13 \\
\hline Sandblast & 9 & 6 & 2 & 86.50 & 67 & 108.89 & 85.13 \\
\hline Trimming & 6 & 6 & 2 & 84.35 & 67 & 67.60 & 83.30 \\
\hline
\end{tabular}

Table 2 displays the environmental sound pressure levels, the number of stations, blind spots, and various types of stations based on their measured sound pressure level. The lowest and highest sound pressure levels were recorded in the curing unit (81.7 dBA and $92.8 \mathrm{dBA}$, respectively). The curing unit had the largest number of stations whose sound pressure levels exceeded the standard limit (85 $\mathrm{dBA}$ ). Likewise, it also had the largest number of stations with sound pressure levels below the standard limit (65 dBA).

Table 2: The results of measuring environmental sound pressure level in the curing unit

\begin{tabular}{|c|c|c|c|c|c|c|c|c|c|c|c|}
\hline Unit & $\begin{array}{c}\text { Number } \\
\text { of } \\
\text { workers }\end{array}$ & $\begin{array}{l}\text { Number of } \\
\text { measurement } \\
\text { stations }\end{array}$ & $\begin{array}{l}\text { Number } \\
\text { of blind } \\
\text { spots }\end{array}$ & $\begin{array}{c}\text { Minimum } \\
\text { SPL } \\
{[\mathrm{dBA}]}\end{array}$ & $\begin{array}{l}\text { Maximum } \\
\text { SPL } \\
{[\mathrm{dBA}]}\end{array}$ & $\begin{array}{r}\text { Static } \\
\text { with S } \\
\text { over } \\
\text { dB }\end{array}$ & $\begin{array}{l}\text { ns } \\
\text { PLs } \\
85\end{array}$ & $\begin{array}{r}\text { Static } \\
\text { with S } \\
\text { betw } \\
65 \text { and } \\
\text { dB }\end{array}$ & $\begin{array}{l}\text { ns } \\
\text { PLs } \\
\text { en } \\
85 \\
\end{array}$ & $\begin{array}{r}\text { St } \\
\text { witl } \\
\text { Ic } \\
\text { th }\end{array}$ & $\begin{array}{l}\text { ons } \\
\text { SPLs } \\
\text { rer } \\
65 \\
\text { A } \\
\end{array}$ \\
\hline \multirow{2}{*}{ Curing } & \multirow{2}{*}{51} & \multirow{2}{*}{81} & \multirow{2}{*}{99} & \multirow{2}{*}{81.7} & \multirow{2}{*}{92.8} & $\%$ & No & $\%$ & No & $\%$ & No \\
\hline & & & & & & 69.13 & 56 & 30.87 & 25 & 0 & 0 \\
\hline Sandblast & 9 & 12 & 12 & 82.9 & 89.5 & 100 & 12 & 0 & 0 & 0 & 0 \\
\hline Trimming & 6 & 8 & 8 & 83 & 87.5 & 100 & 8 & 0 & 0 & 0 & 0 \\
\hline Total & 66 & 101 & 119 & 82.53 & 89.93 & 75.25 & 76 & 24.75 & 25 & 0 & 0 \\
\hline
\end{tabular}

To project sound map in natural conditions, safe area $(\mathrm{SPL}<65 \mathrm{dBA})$ is usually demonstrated in green, caution area $(65<\mathrm{SPL} \leq 85 \mathrm{dBA})$ is marked yellow, and danger area ( $\mathrm{SPL}>85 \mathrm{dBA}$ ) is marked red. However, in the curing hall, all measurement results showed sound pressure levels above 81 $\mathrm{dBA}$, whereas no sound pressure level below 65 $\mathrm{dBA}$ was recorded. Therefore, to better illustrate 
caution and danger areas in the hall and have a better understanding of the projected map, white $(81.5<\mathrm{SPL} \leq 84.2 \mathrm{dBA})$, pale yellow $(84.2<\mathrm{SPL} \leq$ $87.8 \mathrm{dBA})$, light orange (87.8 < SPL $\leq 90.5 \mathrm{dBA})$, and red (SPL > 90.5 dBA) were used. The same colors were also used to project the sound map using Noise At Work. The following figure demonstrates the sound map of the curing hall, sandblast unit, and trimming unit. The map contains noise generating sources, caution areas, and danger areas.

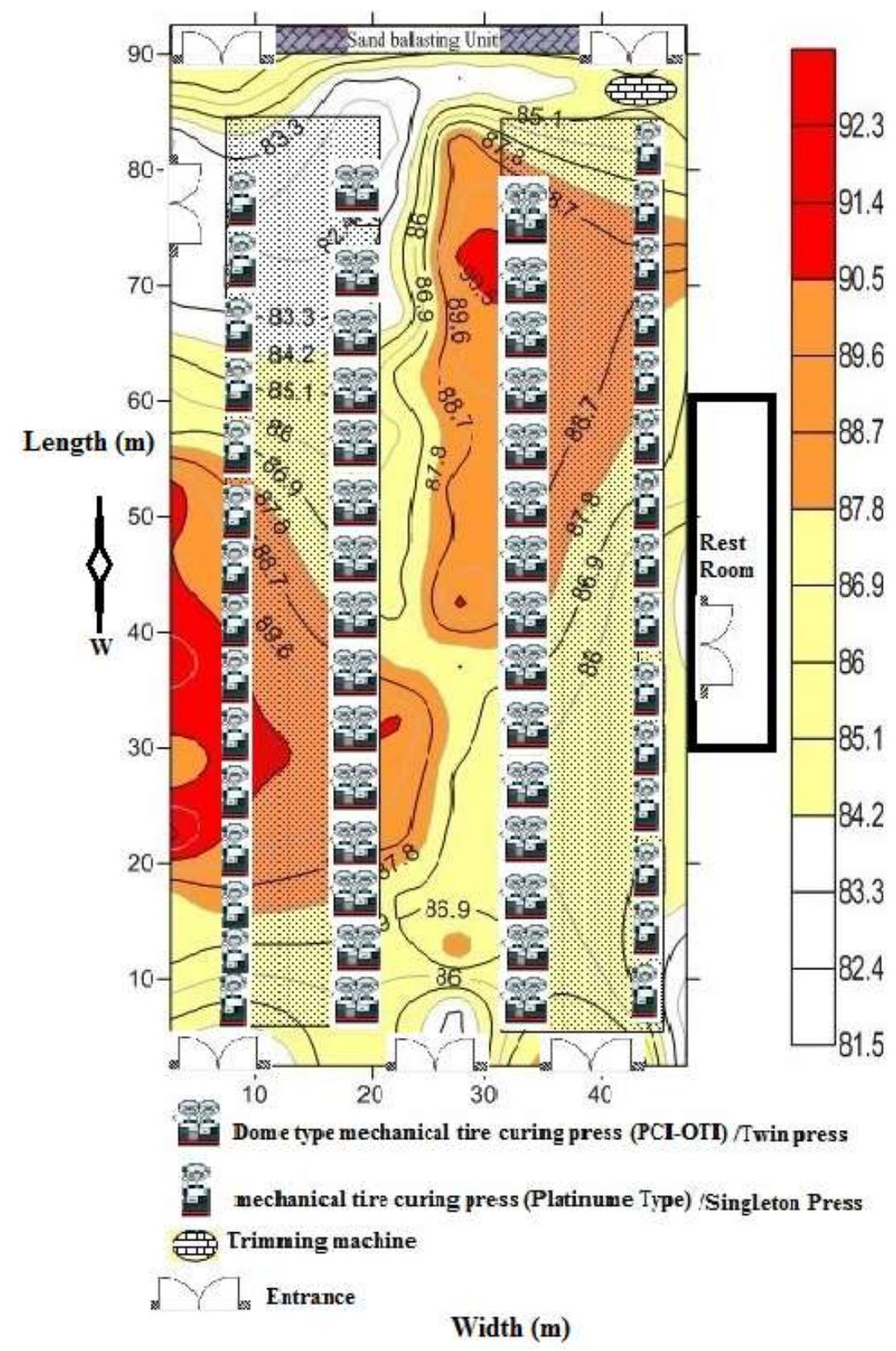

Figure 1: Sound and isosonic map using Surfer

Figure 2 displays the sound map of the curing hall, sandblast unit, and trimming unit. The map contains noise generating sources, caution areas, and danger areas. There were 66 workers. The figure further demonstrates the location of different machines (twin curing press, singleton curing press, and trimming machine). 


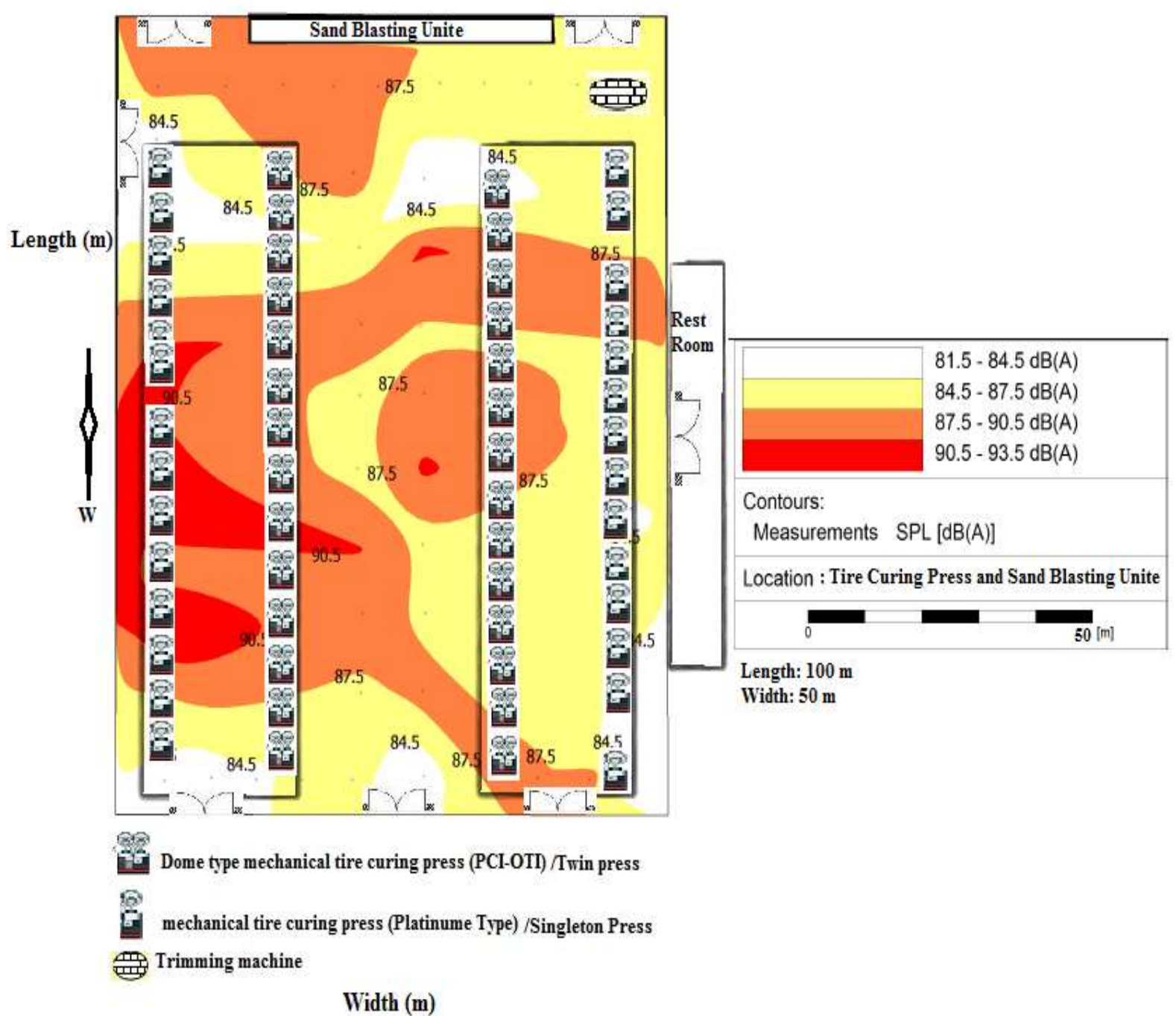

Figure 2: Sound and isosonic map using Noise At Work

\section{Discussion}

The current study assessed personal and environmental sound pressure levels and projected the sound map of an Iranian tire manufacturing complex using Surfer V.14 and Noise At Work in 2018. As illustrated in (Table 1), the results of all morning shift workers' dosimetry showed that the average 8-hour equivalent sound levels in the curing, sandblast, and trimming units were 87.13, 85.37, and $83.30 \mathrm{dBA}$, respectively. Therefore, the curing unit is the most dangerous part of the complex with regard to the equivalent sound level. The workers' average equivalent sound levels in the curing and sandblast units exceeded the standard limit by 2.13 and $0.37 \mathrm{~dB}$, respectively. In the trimming unit, however, the equivalent sound level fell within the standard range (though it was greater than $80 \mathrm{dBA}$ ). Moreover, the degrees of received dose in the curing, sandblast, and trimming units were $163.30 \%, 108.89 \%$, and $67.60 \%$, respectively. Thus, the received dose of the curing unit was 1.63 times greater than the permissible limit, making this unit the noisiest unit of the complex. Aliabadi et al. (2015) studied personal and environmental sound pressure level in a steel factory. The results of dosimetry showed that recorded doses in the iron casting, furnace, crystal, bag filter, and cooling tower were 2.9, 2.82, 2.4, 2.3, and 1.8 times greater than the standard limit. The highest noise was also recorded in furnace (36).

As indicated in Table 2, the highest (81.7 dBA) and lowest (92.8 dBA) sound pressure levels were recorded in the curing unit. In addition, the average sound pressure level in the curing unit was $86.51 \mathrm{~dB}$ (SD = 2.66). Golmohammadi et al. (2017) determined the noise control prioritizing index (NCPI) in 11 units of a tire manufacturing company. The results of environmental measurements showed that $22.9 \%$ of the investigated stations had a noise level within the danger zone and the others stations had a noise level within the caution zone (77.1\%). Also the curing unit with 20 employees had the highest noise control priority index (NCPI=1.369) (15). In addition, Farhang Dehghan et al. (2012) assessed the personal and environmental sound pressure levels in a petrochemical complex. The results of dosimetry showed that the average 8-hour equivalent sound levels in the water, air, and power plant units were 81.7, 89.2, and 82.5 dBA, respectively. Hence, the air unit was found to be the most dangerous unit in terms of noise pollution (37). They argued that the 
major noise generating devices in the petrochemical industry should be identified and prioritized with respect to implementing noise control measures. As indicated in Figures 1and 2, out of the 220 stations, measurements were conducted only in 101 stations (45.9\%) and the rest of the stations were skipped as blind spots. The largest number of measurement and blind stations was located in the curing unit (81 and 99 stations, respectively). Overall, 56 stations $(69.13 \%)$ of the curing unit were registered as danger areas (with SPLs greater than $85 \mathrm{dBA}$ ). There were also 24 and 16 measurement stations in the sandblast and trimming units, respectively, accounting for $50 \%$ of all the identified stations in the two units. In all the measurement stations, the recorded sound pressure levels were greater than $85 \mathrm{~dB}$. On the other hand, the average sound pressure levels of the three units were less than $81 \mathrm{~dB}$. Taken together, 76 measurement stations in the three units $(75.25 \%$ of all measurement stations) had registered sound pressure levels above $85 \mathrm{~dB}$, indicating the presence of excessive noise in these units.

Golmohammadi et al. (2009) investigated the emission features of three noise sources (i.e. compressors, pumps, and control valves) and presented a noise control measure for the control and isomax units of Tehran Oil Refinery Complex. The results showed that the weighted pressure level and maximum noise produced by these sources were higher than the standard limit (38). The findings of their study confirm the results of the current research. Nasiri et al. (2007) also assessed noise pollution in Lavan Island (an oil extraction region in Persian Gulf), with the projected sound maps indicating that sound pressure level was higher than the standard limit (39), a finding that is in line with the results of the present study. In another study, Golshah (1997) examined engineering control measures in Isfahan Petrochemical Complex. The results showed that the average sound pressure level in the majority of units of this complex exceeded the standard limit. In fact, a lot of noise is produced in oil and petrochemical industry. This can be attributed to the type of production process, and the presence of air and vapor in the system as the driving force of engines/compressors and thermal exchange. The major proportion of noise is generated by the movement of fluids and pipes as well as the rotation of engines and compressors during the refining process (34). The results of this latest study further corroborate the findings of the current study. Analyzing sound frequency in the frequency range of $C$ showed that the highest sound pressure level (the dominant frequency) $(4000 \mathrm{~Hz})$ was recorded in the curing unit. Jahangiri et al. (2014) conducted a study to discover the best procedures for controlling noise in the water pumps of a thermal power plant. In their study, the researchers measured the sound power level following ISO 3746 (the sound power level of the main pump was 107 $\mathrm{dB}$ and that of the gear box was $108 \mathrm{~dB}$ ). They further analyzed the network noise frequency and projected the sound map using Surfer. Subsequently, they designed and installed a steel chamber covered by plastic foam for the water pump. After that, they measured its effectiveness in noise control (35). Their results are not in line with the findings of this study, which can be attributed to the different processes in the industry they studied, the nature of major noise generating sources, and the quantity and variety of machines used in power plants.

\section{Conclusion}

The results of the present study concerning personal exposure to occupational noise of the units showed that the workers were exposed to continuous noise above the standard limit. Given the highest dose of exposure to noise in the curing unit $(163.30 \%)$, it is regarded as the most dangerous area with respect to the degree of noise pollution. Furthermore, the environmental sound level in the curing unit was higher than that of the other two units of the tire manufacturing complex, exceededing the standard limit. Thus, the curing unit should receive priority in in terms of taking noise control measures such as separating the noisy area from other workspaces by a sound-reducing partitioning, equipping noisy machinery with soundabsorbing materials,avoiding metal-to-metal contact by using plastic bumpers, using absorbent lining on surfaces to cushion the fall or impact of objects.

Fitting sound-absorbing materials to hard reflective surfaces, using acoustical silencers in intake and exhaust systems, using rubber mounts to isolate vibrating noise source and separate it from the support surface to maintaine optimum speed of machinery or its particular components. Repairing and replacing loose rotating parts, worn bearings and gears, using sound-absorbing materials on walls, ceiling, and floors to reduce the noise level due to reverberation. Undertaking regular maintenance on equipment (very effective in reducing noise emission if carried out regularly), and applying hearing conservation programs for workers in this industry (e.g, hazard identification and exposure monitoring, control methods (using the hierarchy of controls). Hearing protection devices (selection, use, and maintenance), audiometric testing, hazard communication, 
education, and training, recordkeeping, and continuous monitoring and improvement (program review).

\section{Acknowledgement}

This article was compiled based on a research proposal with project code (96000891). We should express our gratitude to the CEO and HSE manager of the tire manufacturing factory. We are also indebted to all the personnel who kindly participated in this study.

Conflict of interest: None declared.

\section{References}

1. Nassiri $P$, Zare $S$, Monazzam MR, Pourbakht A. A Model to Determine the Level of Serum Aldosterone in the Workers Attributed to the Combined Effects of Sound Pressure Level, Exposure Time and Serum Potassium Level: A Field-Based Study. Jundishapur Journal of Health Sciences 2017; 9(2):e38167.

2. Zare S, Nassiri P, Monazzam MR, Pourbakht A, Azam K, Golmohammadi T. Evaluation of the effects of occupational noise exposure on serum aldosterone and potassium among industrial workers. Noise Health 2016; 18(80):1-6.

3. Nassiri P, Zare S, Monazzam MR, Pourbakht A, Azam K, Golmohammadi T. Modeling signal-tonoise ratio of otoacoustic emissions in workers exposed to different industrial noise levels. Noise Health 2016; 18(85):391-8.

4. Indrianti N, Biru NB, Wibawa T. The Development of Compressor Noise Barrier in the Assembly Area (Case Study of PT Jawa Furni Lestari). Procedia CIRP 2016; 40:705-10.

5. Hosseinpour R, Jafari Naeimi K, Ghotbi Ravandi MR. Evaluation of Noise Pollution Levels Due to Four-Wheel Harvesting Machines in Bystanders and Machine Drivers. Journal of Health and Development 2015; 4(1):52-64.

6. Van Kempen EE, Kruize $\mathrm{H}$, Boshuizen $\mathrm{HC}$, Ameling CB, Staatsen BA, de Hollander AE. The association between noise exposure and blood pressure and ischemic heart disease: a metaanalysis. Environ Health Perspect 2002; 110(3):307-17.

7. Tomei G, Fioravanti M, Cerratti D, Sancini A, Tomao E, Rosati MV, et al. Occupational exposure to noise and the cardiovascular system: a meta-analysis. Sci Total Environ 2010; 408(4):681-9.

8. Burgess GL, Dippnall WM, Ravandi MR, Cherry NM. Retrospective noise estimates for British nuclear workers using an alternative approach. Ann Occup Hyg 2004; 48(2):117-27.

9. Virkkunen $\mathrm{H}$, Kauppinen $\mathrm{T}$, Tenkanen L. Longterm effect of occupational noise on the risk of coronary heart disease. Scand J Work Environ Health 2005; 31(4):291-9.
10. Davies HW, Teschke K, Kennedy SM, Hodgson MR, Hertzman C, Demers PA. Occupational exposure to noise and mortality from acute myocardial infarction. Epidemiology 2005; 16(1):25-32.

11. Platon SN, Hionis CA. Preventing risk of noise exposure in working environment using noise mapping. Environ Eng Manag J 2014; 13(6):1349-54.

12. Khaldari F, Khanjani N, Bahrampour A, Ghotbi Ravandi MR, Arabi Mianroodi AA. The Time of Hearing Loss Onset among Workers in the Copper by-Industry and its Effective Factors. International Journal of Occupational Hygiene 2016; 8(3):172-8.

13. Zare $\mathrm{S}$, Hasheminejad $\mathrm{N}$, Elahi Shirvan $\mathrm{H}$, Hasanvand D, Hemmatjo R, Ahmadi S. Assessing Individual and Environmental Sound Pressure Level and Sound Mapping in Iranian Safety Shoes Factory. Romanian Journal of Acoustics and Vibration 2018; 15(1):20-5.

14. Concha-Barrientos M, Campbell-Lendrum D, Steenland K. Occupational noise: assessing the burden of disease from work-related hearing impairment at national and local levels. Geneva: World Health Organization, Environmental burden of disease; 2004. Report No.: series, No. 9. Available from: https://www.who.int/quantifying_ehimpacts/publi cations/9241591927/en/

15. Golmohammadi R, Moazaz F, Aliabadi M. The noise control prioritizing index in a tire manufacturing company. Journal of Occupational Hygiene Engineering 2017; 4(3):41-8.

16. Workplace Health and Safety. Managing noise and preventing hearing loss at work. Queensland: Workplace Health and Safety, Office of Industrial Relations; 2011. Available from:https://www.worksafe.qld.gov.au/_data/as sets/pdf_file/0009/58176/Noise-preventinghearing-loss-COP-2011.pdf

17. Platon SN, Tudor A. Noise Control on Locomotive Driver Workingstation. Romanian Journal of Acoustics and Vibration 2014; 11(1):71-4.

18. Freivalds A, Niebel B. Niebel's Methods, Standards, \& Work Design. 13th ed. New York, United States: McGraw-Hill Education; 2013.

19. Freivalds A, Niebel B. Niebel's Methods, Standards, \& Work Design. 12th ed. New York, United States: McGraw-Hill Education; 2008.

20. Mediastika CE. Akustika Bangunan: PrinsipPrinsip dan Penerapannya di Indonesia. 1st ed. Jakarta: Penerbit Erlangga; 2005.

21. Atmaca E, Peker I, Altin A. Industrial Noise and Its Effects on Humans. Pol J Environ Stud 2005; 14(6):721-6.

22. Esmailzadeh E, Hakimi H, Farrokhi $M$. Measurement and evaluation of Noise pollution at grinding and flotation units of concentration plant. Paper presented at: The 6th Conference 
on Safety, Health and Environment in Mines and Related Industries; 2006 May 9-11; Tehran, Iran.

23. Hakimi H, Alimohammadi $T$, Farrokhi $M$. Modeling and providing control of noise pollution of the enclosures around the Sarcheshmeh Copper Concentration Plant using the SOUND PLAN software. Paper presented at: The 6th Conference on Safety, Health and Environment in Mines and Related Industries; 2006 May 9-11; Tehran, Iran.

24. NoiseAtWork: fast and easy reporting of measurements as contour maps. [Internet]. 2019 [cited 2019]. Avaible from: https://dgmrsoftware.com/products/noiseatwork/

25. International Organization for Standardization. Acoustics-Determination of occupational noise exposure--Engineering method. Geneva, Switzerland: International Organization for Standardization; 2009. Report No.: ISO 9612.

26. Hojati M, Golmohammadi R, Aliabadi M. Determining the Noise Exposure Pattern in a Steel Company. Journal of Occupational Hygiene Engineering 2016; 2(4):1-8.

27. Golmohammadi R. Noise and vibration engineering. 3rd ed. Hamedan: Daneshjoo; 2007.

28. Monazzam MR, Farhang Dehghan S, Nassiri P, Jahangiri $M$. Determination of the dominant sound source in an air production plant of a petrochemical industry and assessing the effectiveness of its encosing. Tibbi-i-kar 2015; 7(2):44-56.

29. Jahangiri $M$, Golmohammadi R, Aliabadi $M$. Determination of Main Noise Sources in a Thermal Power Plant. Journal of Health and Safety at Work 2014; 4(3):13-22.

30. Zare S, Nassiri P, Monazzam MR, Pourbakht A, Azam K, Golmohammadi T. Evaluation of Distortion Product Otoacoustic Emissions (DPOAEs) among workers at an Industrial Company exposed to different industrial noise levels in 2014. Electron Physician 2015; $7(3): 1126-34$.
31. Thiery L, Ognedal T. Note about the Statistical Background of the Methods Used in ISO/DIS 9612 to Estimate the Uncertainty of Occupational Noise Exposure Measurements. Acta Acust United Acust 2008; 94(2):331-4.

32. Monazzam MR, Golmohammadi R, Nourollahi M, Momen Bellah Fard S. Assessment and control design for steam vent noise in an oil refinery. J Res Health Sci 2011; 11(1):14-9.

33. Golmohammadi R, Monazzam MR, Nourollahi M, Nezafat A, Momen Bellah Fard S. Evaluation of noise propagation characteristics of compressors in Tehran oil refinery center and presenting control methods. J Res Health Sci 2010; 10(1):22-30.

34. Nassiri P, Monazzam M, Farhang Dehghan S. Presenting a model for assessing the environmental and personal noise in a petrochemical plant. Iran Occupational Health 2013; 10(1):23-32.

35. Jahangiri $M$, Golmohammadi $R$, Aliabadi $M$, Jalali M. Noise control of feed water pumps in a thermal power plant. Iran Occupational Health 2017; 14(1):81-92.

36. Aliabadi M, Darvishi E, Shafikhani A. Assessment of the Environmental Sound Level and the Noise Exposure in a Steel Industry. Health System Research 2015; 11(2):327-37.

37. Farhang Dehghan S, Monazzam MR, Nassiri P, Haghighi Kafash Z, Jahangiri M. The Assessment of Noise Exposure and Noise Annoyance at a Petrochemical Company. Journal of Health and Safety at Work 2013; 3(3):11-24.

38. Monazzam MR, Nezafat A, Golmahamadi R, Nourollahi M. Noise characteristics of pumps at Tehran's oil refinery and control module design. Pak J Sci Ind Res 2009; 52(3):167-72.

39. Nassiri P, Zare M, Golbabaei F. Evaluation of noise pollution in oil extracting region of Lavan and the effect of noise enclosure on noise abatement. Iran Occupational Health 2007; $4(3): 49-56$. 